\title{
Population genetic screening: current issues in a European country
}

\author{
Laurent Pasquier $\mathbb{1}^{1,2} \cdot$ Bertrand Isidor $^{3} \cdot$ Emmanuelle Rial-Sebbag $^{4} \cdot$ Sylvie Odent $^{5} \cdot$ Guy Minguet $^{6} \cdot$ \\ Grégoire Moutel ${ }^{2,7}$
}

Received: 30 January 2019 / Revised: 20 March 2019 / Accepted: 16 April 2019 / Published online: 8 May 2019

(c) European Society of Human Genetics 2019

In 2016, in France, the first two high-throughput sequencing platforms, each with an announced annual capacity of 18 000 genomes, ${ }^{1}$ were put in place as part of the French Genomic Medicine Plan (PFMG). ${ }^{2}$ This confirmed the technical feasibility of studying people's genetic characteristics (hereafter referred to as 'genetic testing') on a very large scale. These platforms were designed to provide patients and families with better and faster access to genetic testing (for rare diseases, cancers, diabetes, etc.). However, technical advances and this new infrastructure raise questions about the conditions under which they will be prescribed, access to the production of genetic data (primary and secondary findings), and their integration into clinical practice and human relationships (with patients and relatives), since many areas of medicine well beyond medical genetics will be involved.

Therefore, in the near future, technical advances in studying the genome will make widespread genetic screening possible for healthy subjects at various life stages:

In adults: Currently, genetic tests are performed in the context of a standardised clinical or familial indication: in

\footnotetext{
${ }^{1}$ Press release of the Prime Minister, 17 July 2017 https://www. gouvernement.fr/sites/default/files/document/document/2017/07/ communique_de_presse_de_m._edouard_philippe_premier_ministre_plan_medecine_france_genomique_2025_-_17.07.2017.pdf

${ }^{2}$ French Medical Genome Plan 2025 - report submitted to the Prime Minister on 22 June 2016
}

Laurent Pasquier

laurent.pasquier@chu-rennes.fr

1 Service de Génétique Clinique, Centre Référence "Déficiences Intellectuelles de causes rares" (CRDI), Centre Hospitalier Universitaire Rennes, 16 boulevard de Bulgarie, F-35203 Rennes, France

2 INSERM U1086, Anticipe, Normandie Université, 3 avenue du Général Harris, F-14076 Caen, France

3 Service de Génétique Médicale, Centre Hospitalier Universitaire Nantes, 9 quai Moncousu, F-44093 Nantes cedex 1, France
Europe, these tests must be in a regulatory ${ }^{3}$ or professional database [1]. But, there is a controversy about the secondary findings (whose subjects are healthy when the genetic test is prescribed) as many propose they should be systematically looked for [2] while others remain skeptical (see B. Isidor et al. in this journal).

In children: newborn metabolic and/or genetic screening targeting specific diseases has been being used effectively for over 50 years. International professional recommendations have already been issued that are aimed at restricting these tests to diseases for which treatment or prevention is available [3]. In fact, new technologies could lead to reconsidering the list of screened diseases, expanding it to include diseases for which no treatment or prevention yet exists [4].

During the prenatal period: Currently, noninvasive prenatal testing (NIPT) for Down Syndrome is routinely offered to identify a high probability (>1/1000) of this chromosomal abnormality, detected by serum markers coupled with ultrasound. Techniques starting as early as 5 weeks of pregnancy using foetal cells taken from the cervix are being developed [5]. By combining NIPT with

\footnotetext{
3 Additional Protocol to the Convention on Human Rights and Biomedicine concerning Genetic Testing for Health Purposes, Strasbourg, 27/11/2008 (http://conventions.coe.int/Treaty/fr/Trea ties/html/203.htm) This Protocol was signed by France in 2001 but has not yet been ratified as of this date. The Protocol took effect on 1 July 2018
}

4 INSERM UMR 1027, Toulouse Université, 37 allée Jules Guesde, F-31000 Toulouse, France

5 Service de Génétique Clinique, Centre Référence Anomalies du Développement CLAD Ouest, Centre Hospitalier Universitaire Rennes, 16 boulevard de Bulgarie, F-35203 Rennes, France

6 Institut Mines Télécom Atlantique, Département Sciences Sociales et de Gestion, 4 rue Alfred Kastler, F-44307 Nantes Cedex 3, France

7 Espace régional de Réflexion Ethique, Médecine légale et droit de la santé, Centre hospitalo-universitaire de Caen, Avenue de la Côte de Nacre, F-14033 Caen, France 
high-throughput sequencing (exome/genome), any chromosomal rearrangement or Mendelian disorder can be detected before the time limit for abortion, potentially allowing women to decide freely whether to continue their pregnancy.

Before conception: These genetic tests could technically be offered to all couples before pregnancy to detect genetic variants that could result in disability or disease, especially when its prevalence in the general population is considered high enough. Why is it acceptable for a second child, i.e., preimplantation genetic diagnosis or abortion for a medical reason related to a prenatal diagnosis, but not acceptable for a first pregnancy? Some governments have already instituted routine preconception screening for willing 'at-risk' couples. ${ }^{4}$

The boom in prenatal, neonatal and adult genetic screening has generated a corpus of solutions for identifying people at risk. The use of these tests could seem legitimate since early screening would prevent sick people from being born and lower the cost of disease management and treatment in various medical fields (such as metabolism, cancer, neurodevelopment) [6].

The Council of Europe (an international organisation promoting human rights in Europe) took up this matter in an additional Protocol to the Oviedo Convention ${ }^{5}$ pertaining to genetic testing for medical purposes adopted in $2008 .{ }^{6}$ This Protocol specifically addresses the conditions for implementing a genetic screening programme. Among other proposals, it requires that their relevance be assessed from a scientific and medical point of view, as well as an ethical one. Moreover, the Protocol proposes a list of indicators for assessing relevance with a focus on allowing the 'population in question to make appropriate personal health or reproductive choices based on the results of the proposed test'. This Protocol is considered as an international treaty thus it has to be signed and ratified by the Council of Europe Members States in order to be mandatory in national legislations. To date this Protocol is only binding for 5 Members States (Montenegro, Norway, Portugal, Republic of Moldova and Slovenia) however, it can also be considered as a reference or guiding or standardising good practices across Europe.

In our opinion, these elements should be considered with additional conditions. In the case of widespread genetic screening, which determines whether a person is normal, there

\footnotetext{
${ }^{4}$ State of Israel for Ashkenazi Jews for the screening of certain metabolic diseases: consulted on 28 August 2017 https://www.health. gov.il/English/Topics/Genetics/checks/Pages/

GeneticTestingRecommendations.aspx

5 The Convention for the Protection of Human Rights and Dignity of the Human Being with regard to the Application of Biology and Medicine: Convention on Human Rights and Biomedicine (ETS No 164), 1997

${ }^{6}$ Additional protocol - op. cit.
}

is a clear risk of changing the frame of reference from the phenotype to the genotype. Then, three urgent questions arise when implementing this policy of life.

First: the paradigm of an increase number of at-risk persons (from 'patients', to 'moderately sick patients', to 'healthy carriers/potential patients', 'healthy/suspected to become sick', 'disease-free') exists and replaces the traditional sick/healthy dichotomy [7]. Thus, we see the development of a new status, the 'patient-in-waiting' between sick and healthy. This status results from not having enough knowledge to determine a phenotype when a genetic condition is first diagnosed [8].

The second is related to the temporality of beings; by attempting to anticipate abnormalities increasingly early, we push them forward in the human life cycle. Under the pretext of more effective prevention or treatment, medicine therefore intervenes in each person's destiny at an earlier and earlier stage.

The third concerns the ethical positioning of each of the players (healthcare providers, parents, children, caregivers) exposed to the genome revolution. Everyone can have his own values, his own logic, which poses axiological dilemmas. Following sociologist Max Weber (1947) this term means that (1) the plurality of visions of prenatal, postnatal testing technologies and (2) the plurality of visions of parentage model both are issues of normative tensions (explicit contradictions, ambivalences, troubles among the healthcare professionals, parents, patients) [9]. Empirical research proves there has been a deep shift in attitudes toward childbearing, parent-child relationships, and the ideal parentage model: promises of biomedical technologies feed this technical utopia, nourishing the ideal of the "perfect newborn' [8]. Access to genome sequencing reminds us of the hidden imperfections that lie latent beneath a normal appearance. The movement toward prediction contributes to a 'political economy of hope' that works both to legitimise investments in the promise of therapies grown out of genomic knowledge and the complicated interaction of the players: geneticists, doctors, politicians, patient and family associations, and the media [10].

All of these questions will require us to consider how to organise care and adapt the healthcare profession to meet the population's needs. Therefore, two considerations should be anticipated and discussed. The first is the need to assess the medical benefit, given the practical uncertainties related to genetic test results. The complexity of interpreting these findings makes them hard to use without appropriate support from a healthcare professional (disclosing test results, explaining them, and providing follow-up, care and prevention, based on the relevance or irrelevance of the genetic data).

The second deals with a societal choice as deployment of population genetic screening falls under policies on living 
organisms. The societal demand for genetic testing outside of a strict medical environment already exists, for public policy needs or by individuals wanting greater control over their own health. Thus, the placement of individuals, rightly or wrongly, in new at-risk groups based on genetics, could challenge the very essence of what it means to be human, with all of our unpredictability, thoughts, and emotions. Genetic assessment does not necessarily lead directly to a social assessment. Life itself (with its various components, constant changes, and possible abnormalities), is a biological fact; the decision on when and why to measure, study, and treat, however, remains a social fact, with all that entails in terms of individual temperament, public policy, and risk and benefit management. Policies on living organisms intervene in our biological lives by attempting to define fact that concerns the attitudes, values, and norms relating to birth, normality, and disease. Along the way, we can observe that biotechnologies are not produced independent of changes in mentalities and relationships to disease in modernised societies. Thus, if we are developing biological and genetic screening at this point, it is because our society prefers to prevent children with disabilities from being born rather than having to take care of them and support them.

This debate requires the participation of several parties, including:

Geneticists, who have a responsibility to reflect deeply on the challenges and implementation of these new technologies. Medical genetics must continue to be a means to improve health - not to select and eliminate, but to support, counsel, treat, and finally, cure.

Citizens and the state, who could fight the drift toward discrimination or even eugenics by robustly supporting services for sick children and adults, as well as research.

Widespread genetic testing could be legally possible provided the medical conditions (consensus about feasibility and benefit) and bioethical duties (consent, prohibition of eugenic and discriminatory practices) have been met. In France, public policies about prenatal diagnosis show this regulation is effective. These regulations are based on the addition of a woman's or a couple's personal choice, the multidisciplinary opinions of experts in a prenatal diagnostic centre and respect for the rule of law. Throughout genetic area, a similar decision-making process should emerge to accommodate scientific progress, between public policies and individual choice.

Acknowledgements This work was funded by the French ministry of Health - DGOS, PREPS-17-0385

\section{Compliance with ethical standards}

Conflict of interest The authors declare that they have no conflict of interest.

Publisher's note: Springer Nature remains neutral with regard to jurisdictional claims in published maps and institutional affiliations.

\section{References}

1. van El CG, Cornel MC, Borry P, Hastings RJ, Fellmann F, Hodgson SV, et al. Whole genome sequencing in health care: recommendations of the European Society of Human Genetics. Eur J Hum Genet. 2013;21:580-4.

2. Green RC, Berg JS, Grody WW, Kalia SS, Korf BR, Martin CL, et al. ACMG recommendations for reporting of incidental findings in clinical exome and genome sequencing. Genet Med. 2013;15:565-74.

3. Howard HC, Knoppers BM, Cornel MC, Wright Clayton E, Sénécal K, Borry $\mathrm{P}$, et al. Whole-genome sequencing in newborn screening? A statement on the continued importance of targeted approaches in newborn screening programs. Eur J Hum Genet. 2015;23:1593-600.

4. Bailey DB Jr, Berry-Kravis E, Gane LW, Guarda S, Hagerman R, Powell CM, et al. Fragile X Newborn Screening: Lessons Learned From a Multisite Screening Study. Pediatrics. 2017;139(Suppl 3): S216-25.

5. Jain CV, Kadam L, van Dijk M, Kohan-Ghadr HR, Kilburn BA, Hartman C, et al. Fetal genome profiling at 5 weeks of gestation after non-invasive isolation of trophoblast cells from the endocervical canal. Sci Transl Med. 2016;8:363re4.

6. Stark Z, Schofield D, Martyn M, Rynehart L, Shrestha R, Alam K, et al. Does genomic sequencing early in the diagnostic trajectory make a difference? A follow-up study of clinical outcomes and cost-effectiveness. Genet Med. 2018. https://doi.org/10.1038/ s41436-018-0006-8.

7. Langeard C, Minguet G. Standardisation des mesures du risque pathologique et individualisation de la prise en charge. Terrains Trav. 2016;28:109-30.

8. Timmermans $\mathrm{S}$ and Buchbinder M Saving babies? The consequences of newborn genetic screening. Chicago: The University of Chicago Press; 2013.

9. Weber Max, Henderson AM, Parsons Talcott. The Theory of Social and Economic Organization. New York: Oxford University Press; 1947.

10. Leibing and Tournay (dir.). Les technologies de l'espoir. La fabrique d'une histoire à accomplir. Laval, Québec: Les Presses de l'Université; 2010. 